\title{
The Influence of Physical Activity on COVID-19 Prevention Among Quarantined Individuals: A Case-Control Study
}

\author{
Abdulelah Almansour', Jumana Alagil ${ }^{2}$, Naela B Alamoudi ${ }^{3}$, Rahmah M Alamrie $^{3}$, Sundus Alarifi ${ }^{4}$, \\ Sarah AlUrifan ${ }^{4}$, Abdullatif Althunyan $\mathbb{D}^{\prime}$, Abdullah Alghumlas', Abdullah Alreedy', Adam Aldhawyan ', \\ Shaher Alshehri $\mathbb{D}^{1}$, Arwa Alumran $\mathbb{D D}^{5}$ \\ 'Family and Community Medicine Department, College of Medicine, Imam Abdulrahman Bin Faisal University, Dammam, Saudi Arabia; ${ }^{2}$ College of \\ Dentistry, Imam Abdulrahman Bin Faisal University, Dammam, Saudi Arabia; ${ }^{3}$ College of Medicine, Imam Abdulrahman Bin Faisal University, Dammam, \\ Saudi Arabia; ${ }^{4}$ General Dentist, Ministry of Health, Dammam, Saudi Arabia; ${ }^{5}$ Health Information Management and Technology, College of Public \\ Health, Imam Abdulrahman bin Faisal University, Dammam, Saudi Arabia
}

Correspondence: Abdulelah Almansour, Family and Community Medicine Department, College of Medicine, Imam Abdulrahman Bin Faisal University, Dammam, 32275, Saudi Arabia, Email ahmansour@iau.edu.sa

Background: Physical activity is a known preventive measure for many worldwide public health issues. The purpose of this study is to assess the association between physical activity and the susceptibility to COVID-19 infection.

Patients and Methods: This was a retrospective matched case-control study involving adult participants quarantined with IAU, Dammam, Saudi Arabia. The total randomized sample of study participants were 142, in which 73 of them were tested positive for COVID-19 test and matched for both age and sex with their respective healthy controls who tested negative for COVID-19 test to determine the risk associated with that exposure.

Results: Several variables are assessed regarding their influence on the susceptibility of COVID-19 infection. Exactly half indicated that they were physically active $(\mathrm{n}=71)$. Physical activity did not show any significant association with COVID-19 contraction $\left(x^{2}=\right.$ $0.254, P=0.614)$ nor self-rated level of physical activity $\left(x^{2}=0.122, P=0.727\right)$. Less than half of the participants who had contact with a COVID-19 patient within 14 days of admission to quarantine appeared to have a significantly higher incidence of positive COVID19 swab results compared to those who did not $\left(x^{2}=27.121, P=<0.001\right)$. While third of the participants who indicated that they have had a contact with someone who have Respiratory symptoms or fever within 14 days before admission were tested positive for COVID-19. Participants with lower educational degrees are more likely to be infected with COVID-19. While the rest of the demographic variables appear to be not significantly related to the likelihood of being COVID-19 infected, these include gender, marital status, employment status, age, and BMI.

Conclusion: The present study showed no significant association between physical activity and susceptibility to COVID-19 infection. We recommend a larger sample size to further clarify the relationship between other variables and susceptibility of COVID-19.

Keywords: physical activity, COVID-19, quarantine, susceptibility, prevention

\section{Introduction}

The world faced a new challenge with the emergency outbreak of severe acute respiratory syndrome coronavirus 2 (SARS-CoV2), which causes coronavirus disease 2019 (COVID-19). It initially appeared in China, where they reported the first case to the World Health Organization (WHO) on 31 December 2019 in Wuhan. On 30 January 2020, the WHO declared a public health emergency of international concern. ${ }^{1}$ Unfortunately, this virus has spread rapidly and aggressively worldwide, creating a pandemic. ${ }^{2}$ COVID-19 has drastically affected the whole world and individuals' lifestyles. ${ }^{3}$

The first COVID-19 case was reported in Saudi Arabia on 2 March 2020. ${ }^{4}$ Several precautions were taken to prevent the spread of infection and protect individuals' health. One of the measures undertaken in Saudi Arabia facilitates the 
safe return of expatriate citizens to their homeland, with efforts being made to self-quarantine in order to restrict movement in the event that such persons have the disease or have been exposed to it. ${ }^{5}$

People infected with COVID-19 may be asymptomatic and could thus greatly contribute to the spread of infection. ${ }^{6}$ Used during the influenza and severe acute respiratory syndrome (SARS) epidemics, quarantine has proven to be one of the most successful and effective measures to limit the spread of contagious disease amidst various pandemic events. ${ }^{7-9}$ It is meant to restrict the activities of people suspected to be infected in whom symptoms have not yet appeared either because such persons are still in the viral incubation period or because they are not actually infected. ${ }^{9}$ Due to quarantine, the community's physical activity dropped significantly, ${ }^{10}$ as people were stuck at home with no access to spaces in which to exercise and adapting sedentary behaviors. ${ }^{11,12}$

It is well established that regular physical activity increases immune function; hence, those who are physically active on a regular basis show a lower incidence and severity of symptoms of and death from numerous viral infections. ${ }^{13,14}$ Specifically, it can be concluded that regular physical activity helps reduce the unsatisfactory effects of COVID-19 on individuals. The immune system is highly responsive to exercise, with exercise intensity and duration mirroring physiological stress. ${ }^{13}$ During global crisis like COVID-19, physical inactivity has an impact not only on human physiology, but also on multiple body systems. For example, physical inactivity has been linked to poor mental health and has been shown to degrade mood profiles. These psychological factors may lower immunity and have a negative impact on healing and recovery. ${ }^{15}$ Several years ago, it was reported that the global prevalence of physically inactive people was higher than that of smokers and that a sedentary lifestyle is potentially associated with a higher risk of death than smoking. ${ }^{16}$ Thus, it is important to measure the effect of physical activity on COVID-19 prevention.

A thorough understanding of the clinical characteristics of COVID-19 aids in mapping the disease, identifying highrisk patients, and future management of the disease. It is hypothesized that increased physical activity can reduce a person's susceptibility to contracting COVID-19. It is important to stratify people according to their likelihood of receiving the intended care required during the quarantine period. Consequently, the purpose of this paper is to provide data and discuss the relationship between physical activity and susceptibility to COVID-19 infection. In addition, this study aimed to evaluate the physical activity levels of infected quarantined individuals for comparison with uninfected individuals in all quarantine programs run by the Imam Abdulrahman Bin Faisal University (IAU) in the Eastern Province, Saudi Arabia.

\section{Materials and Methods}

This was a retrospective matched case-control study involving adult participants quarantined with IAU, Dammam, Saudi Arabia from April to June 2020. All males and females, Saudi and non-Saudi, aged above 18 who arrived from multiple countries to Saudi Arabia, were admitted within our study period, and received a COVID-19 test were included.

Data was obtained from the medical records of IAU Quarantine's data, where participants were stratified to positive swab results and matched with negative swab results participants. The database was designed by the hospital health informatics department for quarantine use. Participants were contacted through phone call interviews to obtain more information related to other variables. Written informed consent was obtained from all participants upon admission time to use their health and sociodemographic data for research purposes. Since the study was conducted using a telephone interview, verbal consent was also obtained from all the respondents prior to the interview to inquire about additional information. The participants were provided with information about the study, including guidelines for withdrawal. Confidentiality was guaranteed regarding all data obtained.

The total number of quarantine data was 1846, of those, 150 were tested positive for Covid-19, and were matched with 166 controls from the quarantine data to determine the risk associated with exposure. Participants with incomplete data or invalid COVID-19 test results were excluded. Out of the 150 cases, only 73 responded and were willing to participate, and 69 controls (Figure 1). The study complies with the Declaration of Helsinki, and was approved by the Institutional Review Board of IAU (IRB-UGS- 2021-01-154).

Inter-examiner reliability with at least 0.7 for Cohen's kappa value was measured based on interviews with 25 cases that were then included in the final sample. The data extracted from the participants included demographic data, such as age, nationality, marital status, level of education, employment status, body mass index (BMI), COVID-19 test results, 


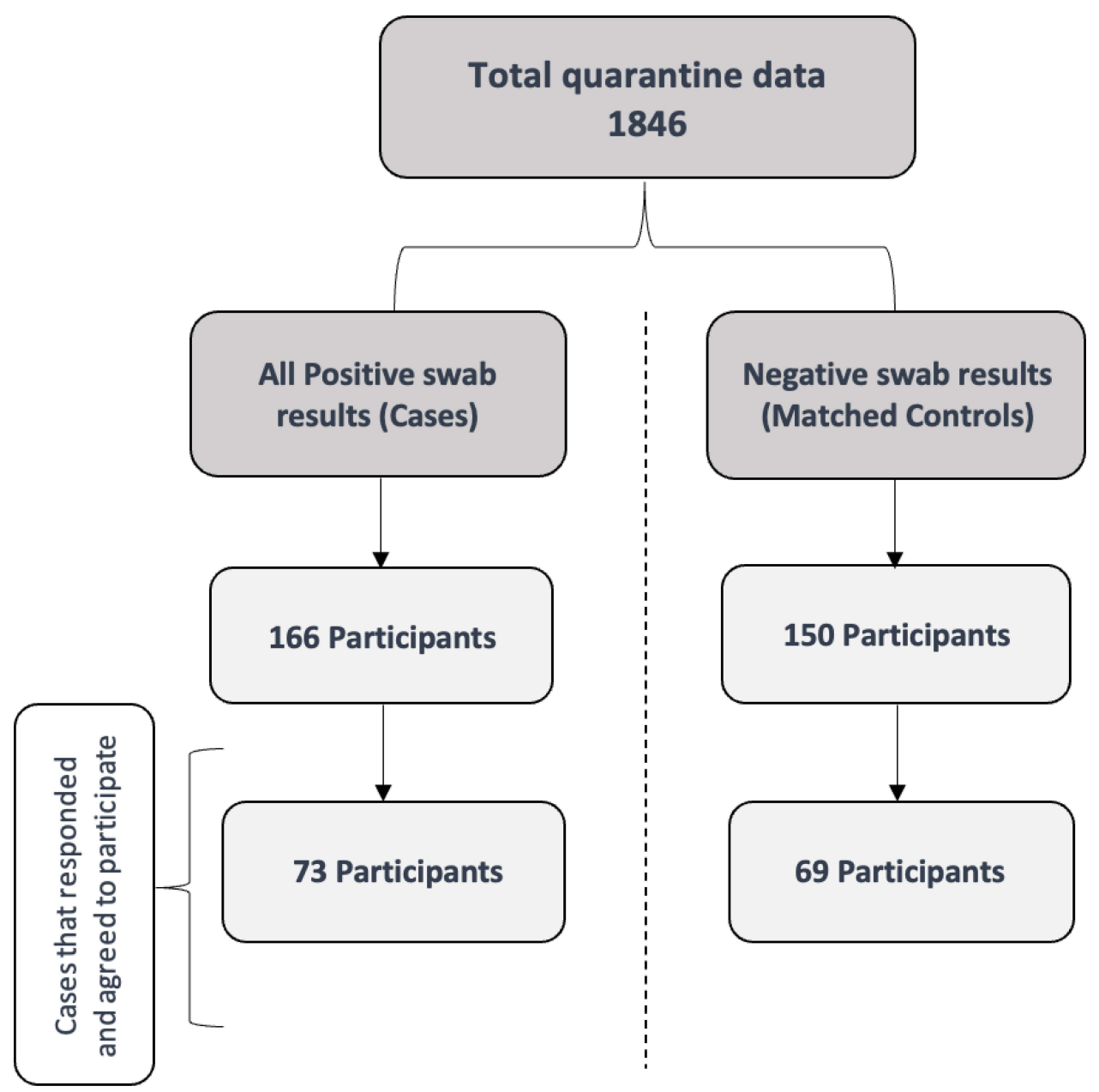

Figure I Sampling process for the case-control study.

reason for quarantine (international arrival, contracted infection, or companion of a person infected with COVID-19), regular exercise (yes or no), and rate of physical activity (low, moderate, or vigorous intensity). Translational validity was ensured by translating Arabic to English, back-translating to Arabic, and then comparing the two versions.

For data analysis, $t$-tests and Chi-square tests were used to compare the two study groups (positive and negative COVID-19 test results) in relation to sociodemographic features and physical activity outcomes. Statistical analysis was performed using SPSS software version $27 .{ }^{17}$

\section{Results}

The study included 142 participants, of whom 73 (51.4\%) tested positive (Table 1). The study included 107 men and 35 women (75.4\%). The study participants' average age was $33.46(\mathrm{SD}=11.16)$. Most participants were Saudis $(\mathrm{n}=130$, 91.5\%). More than half indicated that they were married ( $\mathrm{n}=78,54.9 \%)$.

Most respondents were high school graduates $(n=51,35.9 \%)$, while only $16.2 \%$ were postgraduates $(n=23)$. The majority were employed $(n=89,62.7 \%)$, while only $4 \%$ were retired $(n=6)$. Most quarantined because they arrived from an overseas country $(\mathrm{n}=85,59.9 \%)$, while only $1.4 \%$ were the companion of an infected person $(\mathrm{n}=2)$ (Table 1).

The study participants' average BMI was 27 . Exactly half indicated that they were physically active $(\mathrm{n}=71)$. Half indicated that they were sedentary or engaged in low-intensity activities $(n=35,49.3 \%)$, while the other half reported moderate intensity activity $(\mathrm{n}=36,50.7 \%)$ (Table 1$)$. The majority indicated that their health status was very good $(\mathrm{n}=$ $117,82.4 \%)$. 
Table I Study Participants' Demographic Characteristics

\begin{tabular}{|c|c|c|c|c|}
\hline \multirow[t]{3}{*}{ Variables } & \multirow[t]{3}{*}{ Frequency (\%) } & \multicolumn{2}{|c|}{ Swab Test } & \multirow[t]{3}{*}{ Test (P-value) } \\
\hline & & + & - & \\
\hline & & $n=73(\%)$ & $\mathrm{n}=69(\%)$ & \\
\hline Age (Mean \pm SD) & $33.46 \pm 11.16$ & $32 \pm 11.10$ & $35 \pm 11.20$ & $t=-1.151 \quad(0.252)$ \\
\hline BMI (Mean \pm SD) & $27.42 \pm 5.8$ & $27.55 \pm 6.09$ & $27.28 \pm 5.60$ & $t=0.272(786)$ \\
\hline Gender & & & & $x^{2}=0.603(0.437)$ \\
\hline Male & $107(75.4)$ & $57(78.1)$ & $50(72.5)$ & \\
\hline Female & $35(24.6)$ & $16(21.9)$ & $19(27.5)$ & \\
\hline Nationality & & & & $x^{2}=12.389(<0.001)$ \\
\hline Saudi & $130(9 \mid .5)$ & $61(83.6)$ & $69(100)$ & \\
\hline Non-Saudi & $12(8.5)$ & $12(16.4)$ & $0(0)$ & \\
\hline Marital status & & & & $x^{2}=1.093(0.296)$ \\
\hline Married & $78(54.9)$ & $37(50.7)$ & $4 \mathrm{I}(59.4)$ & \\
\hline Not married & $64(45.1)$ & $36(49.3)$ & $28(40.6)$ & \\
\hline Education & & & & $x^{2}=9.095(\mathbf{0 . 0 2 8})$ \\
\hline High school or lower & $60(42.3)$ & $35(47.9)$ & $25(36.2)$ & \\
\hline Diploma & $16(11.3)$ & II (15.1) & $5(7.2)$ & \\
\hline Bachelor's degree & $43(30.3)$ & $21(28.8)$ & $22(31.9)$ & \\
\hline Postgraduate degree & $23(16.2)$ & $6(8.2)$ & $17(24.6)$ & \\
\hline Employment & & & & $x^{2}=1.335(0.248)$ \\
\hline Unemployed/retired & $37(26.1)$ & $16(21.9)$ & $21(30.4)$ & \\
\hline Employed/student & $105(73.9)$ & $57(78.1)$ & $48(69.6)$ & \\
\hline Reason for quarantine & & & & $x^{2}=78.620(<0.001)$ \\
\hline Contracted COVID-19 in SA & $55(38.7)$ & $54(74.0)$ & I ( 1.4$)$ & \\
\hline International arrival or companion of a COVID-19-infected person & $87(61.3)$ & $19(26.0)$ & $68(98.6)$ & \\
\hline Contact with a COVID- 19 patient & & & & $x^{2}=27.121(<0.001)$ \\
\hline No & $106(74.6)$ & $4 \mid(56.2)$ & $65(94.2)$ & \\
\hline Yes & $36(25.4)$ & $32(43.8)$ & $4(5.8)$ & \\
\hline Contact with someone with respiratory symptoms or fever & & & & $x^{2}=18.929(<0.001)$ \\
\hline No & $112(78.9)$ & $47(64.4)$ & $65(94.2)$ & \\
\hline Yes & $30(21.1)$ & $26(35.6)$ & $4(5.8)$ & \\
\hline How would you rate your health status? & & & & $x^{2}=6.960(0.031)$ \\
\hline Bad/Very bad & $4(2.8)$ & $4(5.5)$ & $0(0)$ & \\
\hline Acceptable & $3(2.1)$ & $3(4.1)$ & $0(0)$ & \\
\hline Good/Very good & $135(95.1)$ & $66(90.4)$ & $69(100)$ & \\
\hline Pets & & & & $x^{2}=4.414(0.036)$ \\
\hline No & |3| (92.3) & $64(87.7)$ & $67(97.1)$ & \\
\hline Yes & II (7.7) & $9(12.3)$ & $2(2.9)$ & \\
\hline Type of pet (if applicable) & & & & $x^{2}=5.958(0.202)$ \\
\hline Bird & $4(2.8)$ & $4(44.4)$ & $0(0)$ & \\
\hline Cat & $4(2.8)$ & $3(33.3)$ & $\mathrm{I}(50)$ & \\
\hline Chicken & $\mathrm{I}(0.7)$ & $I(I I . I)$ & $0(0)$ & \\
\hline Dog & $\mathrm{I}(0.7)$ & $0(0)$ & I (50) & \\
\hline Horse & $\mathrm{I}(0.7)$ & I (II.I) & $0(0)$ & \\
\hline
\end{tabular}

Note: Bold text indicates significant associations. 
Table 2 Association Between Physical Activity and COVID-19 Infection Susceptibility

\begin{tabular}{|c|c|c|c|c|}
\hline \multirow[t]{3}{*}{ Variables } & \multirow{3}{*}{$\begin{array}{c}\text { Frequency } \\
\text { (\%) }\end{array}$} & \multicolumn{2}{|c|}{ Swab Results } & \multirow{3}{*}{$\begin{array}{c}x^{2} \text { Test } \\
(P \text {-value })\end{array}$} \\
\hline & & + & - & \\
\hline & & $n=73(\%)$ & $\mathrm{n}=69(\%)$ & \\
\hline Physically active & & & & $0.254(0.614)$ \\
\hline Yes & $71(50)$ & 35 (47.9) & $36(52.2)$ & \\
\hline No & $71(50)$ & $38(52.1)$ & $33(47.8)$ & \\
\hline Physical activity self-rating & & & & $0.122(0.727)$ \\
\hline $\begin{array}{l}\text { Sedentary or low intensity } \\
\text { activities }\end{array}$ & $35(49.3)$ & $18(47.4)$ & $17(5 \mid .5)$ & \\
\hline Moderate intensity activities & $36(50.7)$ & $20(52.6)$ & $16(48.5)$ & \\
\hline
\end{tabular}

Most of the participants indicated that they had not been in contact with COVID-19-infected patients or with someone who exhibited respiratory symptoms or had a fever within 14 days of their stay $(\mathrm{n}=106,74.6 \%, \mathrm{n}=112,78.9 \%$, respectively) (Table 1). Pet owners were significantly more likely to contract COVID-19 $\left(x^{2}=4.414, P=0.036\right)$. Among the participating pet owners, $81.82 \%$ tested positive for COVID- 19 .

Physical activity did not show any significant association with COVID-19 contraction $\left(x^{2}=0.254, P=0.614\right)$ nor selfrated level of physical activity $\left(x^{2}=0.122, P=0.727\right)$ (Table 2$)$. Persons who reported being physically active were equally likely to become infected as those who were physically inactive in the current study (Figure 2).

Several variables were assessed with regard to their influence on susceptibility to COVID-19 infection (Table 1). All non-Saudis in the study appeared to be infected with COVID-19, while $83.6 \%$ of Saudis were infected $\left(x^{2}=12.389, P=\right.$ $<0.001)$. Participants with lower educational levels were more likely to be infected with COVID-19 $\left(x^{2}=9.095\right.$, $P=0.028$ ), while the other demographic variables, such as gender, marital status, employment status, age, and BMI, appear not to be significantly related to the likelihood of COVID-19 infection.

Less than half of the participants who had contact with a COVID-19 patient within 14 days of admission to quarantine appeared to have a significantly higher incidence of positive COVID-19 swab results compared to those who did not $\left(x^{2}=\right.$

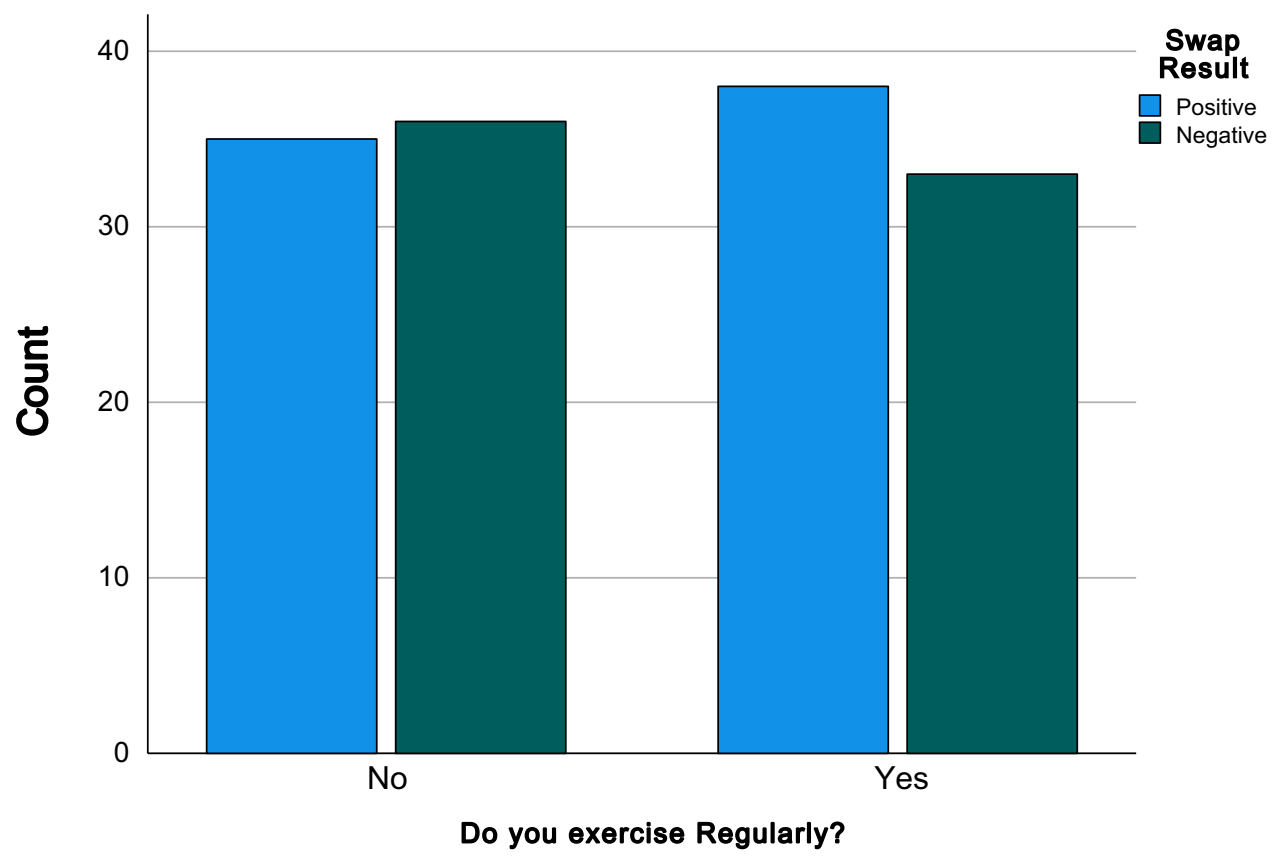

Figure 2 Association between physical activity and COVID-19 infection. 
Table 3 Multivariable Logistic Regression Analysis for the Significant Variables in the Study and Its Association with the COVID-19 Swab Results

\begin{tabular}{|c|c|c|c|c|}
\hline \multirow[t]{2}{*}{ Variables } & \multicolumn{2}{|l|}{ Crude Odds Ratio } & \multicolumn{2}{|l|}{ Adjusted Odds Ratio } \\
\hline & OR & $95 \% \mathrm{Cl}$ & OR & $95 \% \mathrm{Cl}$ \\
\hline \multicolumn{5}{|l|}{ Nationality } \\
\hline Saudi & 1 & & I & \\
\hline Non-Saudi & $1.827(0.999)$ & 0.00 & $492,234,072.13(0.998)$ & 0.00 \\
\hline \multicolumn{5}{|l|}{ Education } \\
\hline High school or lower & 1 & & 1 & \\
\hline Diploma & I.57I (0.45I) & $0.49,5.09$ & $1.008(0.994)$ & $0.12,8.23$ \\
\hline Bachelor's degree & $0.682(0.34 I)$ & $0.31,1.50$ & I.088 (0.894) & $0.32,3.76$ \\
\hline Postgraduate degree & $0.252(0.01 I)$ & $0.09,0.73$ & $1.024(0.974)$ & $0.25,4.14$ \\
\hline \multicolumn{5}{|l|}{ Reason for quarantine } \\
\hline -International arrival or companion of & I & & 1 & \\
\hline a COVID-19-infected person & & & & \\
\hline -Contracted COVID-19 in SA & $193.263(<.001)$ & $25.07,1489.84$ & $165.860(<.001)$ & II.56, 2378.93 \\
\hline \multicolumn{5}{|l|}{ Contact with a COVID-I9 patient } \\
\hline No & 1 & & 1 & \\
\hline Yes & $12.683(<.001)$ & 4.18. 38.50 & $0.405(0.533)$ & $0.02,6.93$ \\
\hline \multicolumn{5}{|l|}{$\begin{array}{l}\text { Contact with someone with } \\
\text { respiratory symptoms or fever }\end{array}$} \\
\hline No & I & & 1 & \\
\hline Yes & $8.989(<.001)$ & $2.94,27.48$ & $2.553(0.430)$ & $0.25,26.15$ \\
\hline \multicolumn{5}{|l|}{$\begin{array}{l}\text { How would you rate your health } \\
\text { status? }\end{array}$} \\
\hline Good/Very good & 1 & & I & \\
\hline Acceptable & $\mathrm{I}, 688,905,517.53(0.999)$ & 0.000 & $41,139,769.99(0.999)$ & 0.000 \\
\hline Bad/Very bad & $\mathrm{I}, 688,905,517.53$ (0.999) & 0.000 & $31,674,571.93(0.999)$ & 0.000 \\
\hline \multicolumn{5}{|l|}{ Pets } \\
\hline No & 1 & & 1 & \\
\hline Yes & $4.7 I I(0.053)$ & $0.98,22.64$ & $4.374(0.168)$ & $0.54,35.72$ \\
\hline \multicolumn{5}{|l|}{ Physically active } \\
\hline No & 1 & & 1 & \\
\hline Yes & $1.184(0.615)$ & $0.613,2.29$ & $0.884(0.85 \mathrm{I})$ & $0.24,3.21$ \\
\hline \multicolumn{5}{|l|}{ Physical activity self-rating } \\
\hline Sedentary or low intensity activities & I & & & \\
\hline Moderate intensity activities & I.I8I (0.727) & $0.46,3.00$ & $1.085(0.916)$ & $0.24,4.96$ \\
\hline Vigorous intensity activities & $0.918(0.836)$ & $0.4 I, 2.06$ & $0.884(0.85 \mathrm{I})$ & $0.24,3.21$ \\
\hline
\end{tabular}

Note: Bold text indicates significant associations.

27.121, $P=<0.001$ ) (Table 1). A third of the participants who indicated that they had contact with someone who exhibited respiratory symptoms or had a fever within 14 days of admission to quarantine tested positive for COVID-19 $\left(x^{2}=\right.$ 18.929, $P=<0.001)$.

In addition, $90 \%$ of the participants who tested positive for COVID-19 indicated that their health status was "good" or "very good," while only $5.5 \%$ (4 participants) indicated that their overall health status was "poor" or "very poor" $\left(x^{2}=\right.$ $6.960, P=0.031)$ (Table 1). 
Further, multivariable logistic regression analysis is conducted to find the differences in the crude and adjusted odds ratio for the significant variables in the bivariate analysis, while the dependent variable in the model is the swab result (Table 3). Several variables were significant at the crude level of analysis, these variables are Education, Reason for quarantine, Contact with someone with covid-19 in the past 14 days prior to quarantine, and Contact with someone with respiratory symptoms or fever 14 days prior to quarantine.

All the above-mentioned variables were no longer significant at the adjusted level of analysis, except the reason for quarantine which stayed significant after adjusting for the rest of the variables in the model. The odds of having a positive swab result if the participant was in the quarantine because they contracted Covid-19 in Saudi Arabia is 166 times higher than if they were in the quarantine because they were international arrivals or being a companion of a COVID-19infected person $(\mathrm{P}=<.001)$.

\section{Discussion}

The present study assessed the association between physical activity and COVID-19 susceptibility. In addition, several demographic factors were assessed for their association with COVID-19 contraction. The assessed participants were all from the quarantine areas managed by IAU in Eastern Saudi Arabia.

The study showed no significant association between physical activity and the possibility of COVID-19 contraction. However, several other factors were significantly correlated with positive COVID-19 swab results. These factors include contact history, education level, pet ownership, and health status.

Although the literature makes extensive mention of physical activity's relationship with immune responses, ${ }^{13-16}$ the current study showed no significant influence of physical activity on the prevention of COVID-19 infection. The current study results differ from those of Maugeri et al, ${ }^{18}$ which showed that regular physical activity significantly improves a person's immune response. Moreover, da Silveira et $\mathrm{al}^{19}$ mentioned that a lack of physical activity can exacerbate psychological conditions, weaken immunity, and increase the likelihood of various infections. This dissimilarity between the current study and the literature can be attributed to the risk of recall bias, altering the interpretation of results. Engaging in physical activity is generally effective to improve a person's overall health.

The current study found that lower education levels are significantly correlated with susceptibility to COVID-19 infection. A study conducted in the United States of America examined factors relevant to perceived COVID-19 susceptibility between urban and rural adults in Alabama. ${ }^{20}$ Scarinci et al ${ }^{20}$ revealed that educational attainment was significantly associated with perceived susceptibility to COVID-19, whereas less educated participants perceived lower susceptibility to COVID-19. The study also showed that people with high school education or less have reduced awareness of the risk of COVID-19 infection. ${ }^{20}$ Nevertheless, recent evidence has shown that educational attainment is positively associated with stronger engagement in healthy behaviors. ${ }^{21}$ Therefore, a lower educational level can be said to be related to increased infection potential due to lower awareness of the risk of infection and hence increased COVID-19 infection susceptibility.

The results of the current study showed a significant association between a history of contact with infected people and positive COVID-19 swab results, regardless of whether the infected people were symptomatic. This result coincided with that of another study conducted in Wuhan, China, where contact with confirmed case patients was one of the definitions of definite exposure. ${ }^{22}$ This association is justified, as several pieces of evidence have proved that COVID-19 is mainly spread through contact and respiratory transmission modes. ${ }^{22-26}$ Nevertheless, Tian et al and Chen et al found this relationship to be insignificant. ${ }^{27,28}$

BMI is an internationally standardized tool used to identify and measure overweight and obesity. BMI is calculated as the ratio of weight in kilograms $(\mathrm{kg})$ to the squared height in meters $\left(\mathrm{m}^{2}\right)$. According to the WHO, BMI scores are categorized into six groups: underweight $\left(<18.5 \mathrm{~kg} / \mathrm{m}^{2}\right)$, normal $\left(18.5-24.9 \mathrm{~kg} / \mathrm{m}^{2}\right)$, pre-obesity $\left(25-29.9 \mathrm{~kg} / \mathrm{m}^{2}\right)$, obesity class I (30-34.9 kg/m ${ }^{2}$, obesity class II $\left(35-39.9 \mathrm{~kg} / \mathrm{m}^{2}\right)$, and obesity class III $\left(>40 \mathrm{~kg} / \mathrm{m}^{2}\right){ }^{29,30}$ The average BMI in our study population was in the pre-obesity range.

In regard to COVID-19 and BMI, our study did not show a statistically significant relationship between BMI and the likelihood of COVID-19 contraction. This is in agreement with López-Bueno et al as they have shown no significant relation between BMI and cardiorespiratory fitness among 89 adolescents. However, they have concluded that it might delay the normal development of maximum oxygen intake levels for the same sample age. ${ }^{31}$ On the contrary, other studies 
have shown that obesity is an emerging independent risk factor for COVID-19. It plays a significant role in disease susceptibility and severity. ${ }^{32}$ Previous data have shown that obesity is related to nearly one-third of hospitalized cases during the pandemic. ${ }^{33}$ Therefore, it can be concluded that a high BMI is associated with a greater risk of COVID-19 complications, and a low BMI is not associated with severe symptoms. ${ }^{30}$ This agrees with Busetto et al, who stated that overweight and obese patients required assisted ventilation and intensive care admission more frequently than normal weight patients, ${ }^{34}$ as well as Hussain et al, who concluded that obesity was significantly associated with COVID-19 mortality [OR: $3.68,95 \% \mathrm{CI}:<0.003] .{ }^{35}$

Furthermore, the impact of the COVID-19 pandemic on eating habits has also been addressed in the literature. One study on the immediate impact of COVID-19 in the Italian population showed increased weight in $48.6 \%{ }^{36}$ The differences between our study and the aforementioned studies could be attributed to our small sample size. Despite this, an ideal BMI is crucial for preventing and reducing poor outcomes of COVID-19 infection.

Lower respiratory tract infections are strongly associated with obesity and a higher BMI. For instance, airway narrowing is caused by the mechanical effects of obesity on the respiratory tract, leading to increased exposure to COVID-19. ${ }^{37}$ Furthermore, obesity is associated with increased levels of inflammatory mediators such as tumor necrosis factor alpha (TNF- $\alpha$ ), interleukin (IL) -8 , IL-6, high-sensitivity C-reactive protein (hs-CRP), and monocyte chemoattractant protein-1 (MCP-1). ${ }^{38}$ These immune system changes predispose obese patients to respiratory infections. $^{15,39}$

The present study has certain limitations that could have been improved upon through the elimination of recall bias regarding responses to questionnaire items about physical activity and body weight. Such bias may have contributed significantly to the data results. Moreover, the data collected may be subject to unintentional operator bias, where respondents answer some questions subjectively. Another limitation is not recording body weight before and after the quarantine period to address habitual trends in BMI changes. Nevertheless, this study could serve as a baseline for future cohort studies involving more confounding factors targeting different regions around the world.

\section{Conclusion}

The present study showed no significant association between physical activity and susceptibility to COVID-19 infection. Other variables, however, were significantly associated with positive COVID-19 swab results, including history of contact with an infected person, lower education level, and having pets.

Although the intensity of physical activity was not found to influence COVID-19 susceptibility in the current study, other studies have shown that it is associated with the severity of the infection. For this reason, we recommend raising awareness within the community through campaigns, including on social media platforms, about the importance of physical activity to prevent and reduce the susceptibility of respiratory infections.

Moreover, our current understanding of physical activity as an independent risk factor for the severity of COVID-19 is based on an observational study with a small sample size. This limited the variability of the data and the generalizability of our results. We therefore recommend a larger sample size and a prospective cohort study design to further clarify the relationship between other variables and COVID-19.

\section{Data Sharing Statement}

Data can be available from the corresponding author upon request.

\section{Ethics Approval and Informed Consent}

Ethical approval is obtained from the Institutional Review Board in Imam Abdulrahman bin Faisal university (IRB-UGS2021-01-154). Participants were asked to verbally consent to participate in the study prior to their participation.

\section{Consent for Publication}

The corresponding author on behalf of the coauthors in the study would like to provide the journal their consent to publish the manuscript. 


\section{Acknowledgments}

The authors would like to acknowledge Editage.com for their great editorial services and excellent proof reading.

\section{Author Contributions}

All authors contributed to data analysis, drafting or revising the article, have agreed on the journal to which the article will be submitted, gave final approval of the version to be published, and agree to be accountable for all aspects of the work.

\section{Funding}

No funding was relevant to this project.

\section{Disclosure}

The authors report no conflicts of interest in this work.

\section{References}

1. World Health Organization. Statement on the Second Meeting of the International Health Regulations (2005) Emergency Committee Regarding the Outbreak of Novel Coronavirus (2019-Ncov). Geneva, Switzerland: World Health Organization; 2020.

2. World Health Organization. Coronavirus disease (COVID-19) - events as they happen [webpage]. Available from: https://www.who.int/emergen cies/diseases/novel-coronavirus-2019/events-as-they-happen. Accessed June 14, 2020.

3. Wilder-Smith A, Freedman D. Isolation, quarantine, social distancing and community containment: pivotal role for old-style public health measures in the novel coronavirus (2019-nCoV) outbreak. J Travel Med. 2020;27(2). doi:10.1093/jtm/taaa020

4. Government of Saudi Arabia. COVID-19 dashboard: Saudi Arabia [webpage]. Available from: https://covid19.moh.gov.sa/. Accessed June 14, 2020.

5. Kingdom of Saudi Arabia. Measures in response to COVID [webpage]. Available from: https:/home.kpmg/xx/en/home/insights/2020/04/saudiarabia-government-and-institution-measures-in-response-to-covid.html. Accessed June 14, 2020.

6. Goumenou M, Sarigiannis D, Tsatsakis A, et al. COVID-19 in Northern Italy: an integrative overview of factors possibly influencing the sharp increase of the outbreak. Mol Med Rep. 2020;22(1):20-32.

7. Cetron M, Simone P. Battling 21st-century scourges with a 14th-century toolbox. Emerg Infect Dis. 2004;10(11):2053-2054. doi:10.3201/ eid1011.040797_12

8. Goh K, Cutter J, Heng B, et al. Epidemiology and control of SARS in Singapore. Ann Acad Med Singapore. 2006;35(5):301-316.

9. Cetron M, Landwirth J. Public health and ethical considerations in planning for quarantine. Yale J Biol Med. 2005;78:325-330.

10. López-Bueno R, Calatayud J, Andersen LL, et al. Immediate impact of the COVID-19 confinement on physical activity levels in Spanish adults. Sustainability. 2020;12(14):5708. doi:10.3390/su12145708

11. Chirico A, Lucidi F, Galli F, et al. COVID-19 outbreak and physical activity in the Italian population: a cross-sectional analysis of the underlying psychosocial mechanisms. Front Psychol. 2020;11:2100.

12. Tornaghi M, Lovecchio N, Vandoni M, Chirico A, Codella R. Physical activity levels across COVID-19 outbreak in youngsters of Northwestern Lombardy. J Sports Med Phys Fitness. 2021;61(7):971-976. doi:10.23736/S0022-4707.20.11600-1

13. Nieman DC, Wentz LM. The compelling link between physical activity and the body's defense system. J Sport Health Sci. $2019 ; 8(3): 201-217$. doi:10.1016/j.jshs.2018.09.009

14. da Silveira MP, da Silva Fagundes KK, Bizuti MR, Starck É, Rossi RC, e Silva DT. Physical exercise as a tool to help the immune system against COVID-19: an integrative review of the current literature. Clin Exp Med. 2021;21(1):15-28. doi:10.1007/s10238-020-00650-3

15. Codella R, Chirico A, Lucidi F, Ferrulli A, La Torre A, Luzi L. The immune-modulatory effects of exercise should be favorably harnessed against COVID-19. J Endocrinol Invest. 2021;44(5):1119-1122. doi:10.1007/s40618-020-01403-5

16. Wen CP, Wu X. Stressing harms of physical inactivity to promote exercise. Lancet. 2012;380(9838):192-193. doi:10.1016/S0140-6736(12)60954-4

17. IBM Corp. IBM SPSS Statistics for Windows (Version 19.0). Armonk, NY: IBM Corp; 2010.

18. Maugeri G, Castrogiovanni P, Battaglia G, et al. The impact of physical activity on psychological health during Covid-19 pandemic in Italy. Heliyon. 2020;6(6):e04315. doi:10.1016/j.heliyon.2020.e04315

19. da Silveira MP, da Silva Fagundes KK, Bizuti MR, et al.Physical exercise as a tool to help the immune system against COVID-19: an integrative review of the current literature. Clin Exp Med. 2020;2021(21):15-28.

20. Scarinci I, Pandya V, Kim Y, et al. Factors associated with perceived susceptibility to COVID-19 among urban and rural adults in Alabama J Commun Health. 2021;46(5):932-941. doi:10.1007/s10900-021-00976-3

21. Margolis R. Educational differences in healthy behavior changes and adherence among middle-aged Americans. J Health Soc Behav. 2013;54 (3):353-368. doi:10.1177/0022146513489312

22. Liu J, Liao X, Qian S, et al. Community transmission of severe acute respiratory syndrome coronavirus 2, Shenzhen, China, 2020. Emerg Infect Dis. 2020;26(6). doi:10.3201/eid2606.200239

23. Chan J, Yuan S, Kok K, et al. A familial cluster of pneumonia associated with the 2019 novel coronavirus indicating person-to-person transmission: a study of a family cluster. Lancet. 2020;395(10223):514-523. doi:10.1016/S0140-6736(20)30154-9

24. Li Q, Guan X, Wu P, et al. Early transmission dynamics in Wuhan, China, of novel coronavirus-infected pneumonia. $N$ Engl $J$ Med. 2020;382:1199-1207. doi:10.1056/NEJMoa2001316 
25. Huang C, Wang Y, Li X, et al. Clinical features of patients infected with 2019 novel coronavirus in Wuhan, China. Lancet. 2020;395 (10223):497-506. doi:10.1016/S0140-6736(20)30183-5

26. Burke R, Midgley C, Dratch A, et al. Active monitoring of persons exposed to patients with confirmed COVID-19 - United States, JanuaryFebruary 2020. MMWR Morb Mortal Wkly Rep. 2020;69(9):245-246. doi:10.15585/mmwr.mm6909e1

27. Tian S, Hu N, Lou J, et al. Characteristics of COVID-19 infection in Beijing. $J$ Hosp Infect. 2020;80:401-406. doi:10.1016/j.jinf.2020.02.018

28. Chen L, Deng C, Chen X, et al. Ocular manifestations and clinical characteristics of 535 cases of COVID-19 in Wuhan, China: a cross-sectional study. Acta Ophthalmol. 2020;98(8):951-959. doi:10.1111/aos.14472

29. World Health Organization. Health topics [webpage]. Available from: http://www.euro.who.int/en/health-topics/disease-prevention/nutrition/ a-healthy-lifestyle/body-mass-index-bmi. Accessed December 5, 2021.

30. Soeroto AY, Soetedjo NN, Purwiga A, et al. Effect of increased BMI and obesity on the outcome of COVID-19 adult patients: a systematic review and meta-analysis. Diabetes Metab Syndr. 2020;14:1897-1904. doi:10.1016/j.dsx.2020.09.029

31. López-Bueno R, Calatayud J, Andersen LL, et al. Cardiorespiratory fitness in adolescents before and after the COVID-19 confinement: a prospective cohort study. Eur J Pediatr. 2021;180:2287-2293. doi:10.1007/s00431-021-04029-8

32. Kassir R. Risk of COVID-19 for patients with obesity. Obes Rev. 2020;21(6):e13034. doi:10.1111/obr.13034

33. Moser JS, Galindo-Fraga A, Ortiz-Hernandez AA, et al. Underweight, overweight, and obesity as independent risk factors for hospitalization in adults and children from influenza and other respiratory viruses. Influenza Respir Viruses. 2019;13(1):3e9.

34. Busetto L, Bettini S, Fabris R, et al. Obesity and COVID-19: an Italian snapshot. Obesity. 2020;28(9):1600-1605. doi:10.1002/oby.22918

35. Hussain A, Mahawar K, Xia Z, Yang W, El-Hasani S. Obesity and mortality of COVID-19. meta-analysis. Obes Res Clin Pract. $2020 ; 14(4): 295$. doi:10.1016/j.orcp.2020.07.002

36. Di Renzo L, Gualtieri P, Pivari F, et al. Eating habits and lifestyle changes during COVID-19 lockdown: an Italian survey. $J$ Transl Med. 2020;18:1-5. doi:10.1186/s12967-020-02399-5

37. Kulcsar KA, Coleman CM, Beck SE, Frieman MB. Comorbid diabetes results in immune dysregulation and enhanced disease severity following MERS-CoV infection. JCI Insight. 2019;4(20). doi:10.1172/jci.insight.131774

38. Dixon AE, Peters U. The effect of obesity on lung function. Expet Rev Respir Med. 2018;12(9):755e67.

39. Kwok S, Adam S, Ho JH, et al. Obesity: a critical risk factor in the COVID-19 pandemic. Clin Obes. 2020;10(6):e12403. doi:10.1111/cob.12403

\section{Publish your work in this journal}

The Journal of Multidisciplinary Healthcare is an international, peer-reviewed open-access journal that aims to represent and publish research in healthcare areas delivered by practitioners of different disciplines. This includes studies and reviews conducted by multidisciplinary teams as well as research which evaluates the results or conduct of such teams or healthcare processes in general. The journal covers a very wide range of areas and welcomes submissions from practitioners at all levels, from all over the world. The manuscript management system is completely online and includes a very quick and fair peer-review system. Visit http://www.dovepress.com/testimonials.php to read real quotes from published authors. 